\title{
Pattern of disinfectants use and their adverse effects on the consumers after COVID-19 outbreak
}

\author{
Kavoos Dindarloo ${ }^{1} \cdot$ Teamur Aghamolaei $^{2} \cdot$ Amin Ghanbarnejad $^{3} \cdot$ Habibollah Turki $^{4} \cdot$ Sommayeh Hoseinvandtabar $^{5}$. \\ Hasan Pasalari ${ }^{6} \cdot$ Hamid Reza Ghaffari $^{1}$ (D)
}

Received: 18 June 2020 / Accepted: 21 September 2020 / Published online: 30 September 2020

(C) Springer Nature Switzerland AG 2020

\begin{abstract}
Background and objective The aim of this study was to investigate the pattern of disinfectants use within outbreak of COVID-19 and estimate their adverse effects on the consumer's health.

Methods In this descriptive-analytical study, 1090 participants were entered into the study without age and gender limitations. A researcher-made electronic checklist containing 43 questions was applied to collect data. The checklist included three sections: demographic characteristics (8 questions), disinfection of body and non-living surfaces (21 questions), and adverse effects of disinfectants on health (15 questions).

Results $87 \%$ of participants used the incorrect proportions of water and alcohol to make this disinfectant available at home. The percentage of people with wrong proportion of sodium hypochlorite was $74.2 \%$. Approximately $42 \%$ of participants experienced at least one disorder on their hands, feet, eyes, respiratory or gastrointestinal systems after sequential uses of disinfectants. The most common disorders among the participants were found to be skin dryness (76.3\%), obsession (42.2\%), skin itching (41.2\%), coughing $(41.1 \%)$, and eyes irritation (39.5\%). The mean frequency of hand washing and hand disinfecting were 15.28 and 10.74 times per a day, respectively, and the clean-up in case of surfaces was 2.99 times a day. The frequency of hand washing and disinfecting in women group (16.4 and 11.2 times a day) were higher than in men (14.0 and 10.3 times a day) group. In addition, these self-care actions in married people (15.6 and 11.0 times a day) were higher compared to those in single people (14.0 and 10.6 times a day).
\end{abstract}

Conclusion Being unaware of participants with instruction for preparation and use disinfectants may harm their health. Therefore, it is suggested that the authorities provide the necessary training program for public through official media.

Keywords COVID-19 $\cdot$ Disinfection $\cdot$ Health effects $\cdot$ Safety

Hamid Reza Ghaffari

Ghaffarihrz@gmail.com

1 Department of Environmental Health Engineering, School of public health, Hormozgan University of Medical Sciences, Bandar Abbas, Iran

2 Cardiovascular Research Center, Hormozgan University of Medical Sciences, Bandar Abbas, Iran

3 Social Determinants in Health Promotion Research Center, Hormozgan Health Institute, Hormozgan University of Medical Sciences, Bandar Abbas, Iran

4 Infectious and Tropical Diseases Research Center, Hormozgan Health Institute, Hormozgan University of Medical Sciences, Bandar Abbas, Iran

5 Student Research Committee, Hormozgan University of Medical Sciences, Bandar Abbas, Iran

6 Department of Environmental Health Engineering, School of Public Health, Iran University of Medical Sciences, Tehran, IR, Iran

\section{Introduction}

Coronaviruses are viruses that can infect the respiratory tract, gastrointestinal tract, liver, and central nervous system of humans, cows, birds, bats, rodents, and other wildlife [1-3]. Coronaviruses, like influenza viruses, are being transmitted by various animal species in the wild. Alpha-coronavirus and beta-coronavirus can infect mammals, and gamma-corona viruses and delta-coronaviruses tend to infect birds, however some types of coronaviruses can also be transmitted to mammals [3].

The serious and applicable measurements were not considered until the outbreak of viruses of severe acute respiratory syndrome (SARS-CoV) in 2002 and 2003 in Guangdong Province, China. The Middle East Respiratory Syndrome (MERS-CoV) coronavirus outbreak posed the greatest threat 
to the public $[4,5]$. However, in early December 2019, the first cases of a syndrome with unknown origin were first identified in Wuhan, Hubei Province, China [6, 7].

The new and emerging coronavirus, which is considered as the seventh member of the coronavirus family $[8,9]$, has been responsible for this respiratory syndrome. Currently, the prevalence of this acute respiratory syndrome, known as COVID-19, has been confirmed, worldwide. The total number of confirmed cases and deaths in the world as of June 9, 2020 was 7,261,476 and 410,972, respectively. In Iran, the total number of cases and death at the same date was reported to be 175,927 and 8425 , respectively [10]. In Iran, the first death contributed to COVID-19 was officially announced by the Ministry of Health and Medical Education on February 19, 2020 [11, 12].

Common symptoms of COVID-19 include fever, cough, shortness of breath and respiratory problems. In more severe cases, the infection can cause pneumonia, severe acute respiratory syndrome, kidney failure, and even death [13].

The two main routes of COVID-19 transmission are respiratory and contact routes. Contact with infected person's respiratory droplets via coughing or sneezing, contact with a person with respiratory symptoms (sneezing, coughing, etc.), and contact with surfaces on which respiratory droplets are located are currently known as the primary pathways of coronavirus transmission [14].

The literature show that the survival of human coronaviruses on surfaces varies from $2 \mathrm{~h}$ to 9 days [15]. Survival time depends on a variety of factors, including surface type, temperature, relative humidity, and pressure. The previous studies showed that effective inactivation (within $1 \mathrm{~min}$ ) using common disinfectants such as ethanol $70 \%$ and sodium hypochlorite is acceptable [14].

Health tips to prevent the spread of COVID-19 include regular hand washing, covering the mouth and nose when coughing and sneezing, full cooking, avoiding close contact with a person who has symptoms of a respiratory illness such as cough and sneezing, and disinfecting surfaces [2].

There are many disinfectants that are effective against covert viruses such as the COVID-19 virus. The most commonly recommended disinfectants are ethanol $70 \%$ and chlorinated disinfectants such as sodium hypochlorite and calcium hypochlorite. After the outbreak of COVID-19 and due to the lack of familiarity of consumers with disinfectants and their preparing methods, the lack of proper training in this field by trustees, and finally profiteering of some people and companies, some poisonings and health problems in disinfectants users have been reported. The aim of this study was to investigate the pattern of consumption for disinfectants by public after the outbreak of coronavirus and compare it with standard protocol. The additional aim of present research was to identify the adverse effects of disinfectants misuse.

\section{Material and methods}

\section{Study design}

This cross-sectional study was performed within March 2020 and April 2020. The research was approved by the Ethics Committee of Hormozgan University of medical sciences (code: IR.HUMS.REC.1398.480). Since there is no previous study in this field, 384 cases were estimated to be studied based on Cohen's table with $5 \%$ error and $80 \%$ power. The participants in the present study were the citizens of Hormozgan province. Hormozgan is a province in the south of Iran. This province includes 13 counties. The population of this province, according to the census in 2017 was estimated to be $177,641,500$. Until 5 June 2020 , the number of people afflicted with COVID-19 in this province was estimated to be 4480 and the mortalities were 56 [16]. No age or gender limitation were considered for participants.

\section{Data collection}

Data were collected by completing questionnaires. Due to the risk of transmitting the coronavirus through paper questionnaire, electronic self-made questionnaire were applied to collect data. The questionnaire consisted of three sections, including demographic characteristics (8 questions), pattern of disinfectants use (30 questions), and health effects of these substances on consumers ( 8 questions). The total number of questions in the questionnaire was 46. Questions were presented individually on the screen of mobile, tablet and computer and respondents were able to enter their answers by touching the corresponding buttons on the screen. Respondents were not able to move on to the next question without completing the previous one, however they were able to go back and change their previous responses.

\section{Statistical analyses}

The collected data were analyzed by SPSS22. Descriptive analysis were employed to describe the frequency, percentage, mean score and standard deviation of obtained data. T-test, one-way ANOVA or their nonparametric equivalences were applied to analyze the data and the differences between groups.

\section{Results and discussion}

\section{Demographic characteristics}

The results of the demographic characteristics of the participants in the study are shown in Table 1. 
Table 1 Demographic characteristics of participants and their pattern for disinfecting hands and surfaces

\begin{tabular}{|c|c|c|c|c|c|c|c|c|c|c|c|c|c|c|c|}
\hline \multirow[t]{2}{*}{ Characteristics } & \multirow[t]{2}{*}{ Statistics } & \multirow[t]{2}{*}{$\mathrm{N}$} & \multirow[t]{2}{*}{ Percent } & \multicolumn{4}{|c|}{ Hand washing frequency } & \multicolumn{4}{|c|}{ Hand sanitizing frequency } & \multicolumn{4}{|c|}{ surface disinfection frequency } \\
\hline & & & & Mean & Min & Max & $\mathrm{p}$ & Mean & Min & Max & $\mathrm{p}$ & Mean & Min & Max & $\mathrm{p}$ \\
\hline \multirow[t]{4}{*}{ Age (year) } & $15-30$ & 343 & 31.5 & 13.87 & 1 & 100 & \multirow[t]{4}{*}{0.076} & 10.06 & 1 & 100 & \multirow[t]{4}{*}{0.231} & 3.15 & 1 & 30 & \multirow[t]{4}{*}{0.633} \\
\hline & $31-45$ & 597 & 54.8 & 15.94 & 1 & 100 & & 11.33 & 1 & 100 & & 2.97 & 1 & 30 & \\
\hline & $46-60$ & 136 & 12.5 & 15.90 & 1 & 100 & & 10.12 & 1 & 60 & & 2.68 & 1 & 30 & \\
\hline & $>60$ & 14 & 1.3 & 15.29 & 3 & 30 & & 6.82 & 3 & 20 & & 3.00 & 1 & 10 & \\
\hline \multirow[t]{2}{*}{ Gender } & Male & 513 & 47.1 & 14.03 & 1 & 100 & \multirow[t]{2}{*}{0.001} & 10.30 & 1 & 60 & \multirow[t]{2}{*}{0.238} & 3.16 & 1 & 30 & \multirow[t]{2}{*}{0.148} \\
\hline & Female & 577 & 52.9 & 16.39 & 1 & 100 & & 11.17 & 1 & 100 & & 2.85 & 1 & 30 & \\
\hline \multirow[t]{4}{*}{ Education } & Under diploma & 94 & 8.6 & 12.79 & 1 & 50 & \multirow[t]{4}{*}{0.123} & 10.21 & 1 & 50 & \multirow[t]{4}{*}{0.496} & 3.49 & 1 & 30 & \multirow[t]{4}{*}{0.094} \\
\hline & Diploma & 228 & 20.9 & 15.12 & 1 & 100 & & 10.51 & 1 & 80 & & 2.91 & 1 & 30 & \\
\hline & Bachelor & 553 & 50.7 & 15.91 & 1 & 100 & & 11.25 & 1 & 100 & & 3.13 & 1 & 30 & \\
\hline & Postgraduate & 215 & 19.7 & 14.90 & 1 & 60 & & 9.86 & 1 & 50 & & 2.53 & 1 & 15 & \\
\hline \multirow[t]{6}{*}{ Employment } & Unemployed & 45 & 4.1 & 11.67 & 1 & 50 & \multirow[t]{6}{*}{0.001} & 8.69 & 1 & 30 & \multirow[t]{6}{*}{0.128} & 2.52 & 1 & 10 & \multirow[t]{6}{*}{0.361} \\
\hline & Retired & 47 & 4.3 & 14.94 & 5 & 30 & & 10.21 & 1 & 30 & & 2.59 & 1 & 25 & \\
\hline & Housewife & 185 & 17.0 & 16.43 & 1 & 100 & & 11.50 & 1 & 100 & & 2.81 & 1 & 15 & \\
\hline & Student & 111 & 10.2 & 11.43 & 1 & 35 & & 7.71 & 1 & 30 & & 3.14 & 1 & 30 & \\
\hline & Employee & 514 & 47.2 & 16.21 & 1 & 100 & & 11.06 & 1 & 100 & & 3.20 & 1 & 30 & \\
\hline & Self- employment & 188 & 17.2 & 14.81 & 1 & 100 & & 11.20 & 1 & 100 & & 2.64 & 1 & 20 & \\
\hline \multirow[t]{2}{*}{ Marital status } & Single & 362 & 21.2 & 14.06 & 1 & 100 & \multirow[t]{2}{*}{0.083} & 10.94 & 1 & 100 & \multirow[t]{2}{*}{0.783} & 3.19 & 1 & 30 & \multirow[t]{2}{*}{0.338} \\
\hline & Married & 728 & 78.8 & 15.60 & 1 & 100 & & 10.69 & 1 & 100 & & 2.94 & 1 & 30 & \\
\hline \multirow[t]{2}{*}{ Have children } & Yes & 728 & 66.8 & 15.84 & 1 & 100 & \multirow[t]{2}{*}{0.028} & 10.90 & 1 & 100 & 0.547 & 3.00 & 1 & 30 & 0.866 \\
\hline & No & 362 & 33.2 & 14.14 & 1 & 100 & & 10.43 & 1 & 100 & & 2.96 & 1 & 30 & \\
\hline Residence place & Rural & 236 & 21.7 & 14.45 & 1 & 100 & 0.236 & 10.74 & 1 & 100 & 1.000 & 3.14 & 1 & 30 & 0.491 \\
\hline & Urban & 854 & 78.3 & 15.50 & 1 & 100 & & 10.74 & 1 & 100 & & 2.95 & 1 & 30 & \\
\hline
\end{tabular}

Of 1090 participants entered into the present study, 513 were male and 577 were female. The mean age of the participants in the study was 35.22 years with a range of 15 to 70 years and the highest frequency was observed in the age group of 31 to 45 years. $21.2 \%$ of the participants were married and $78.8 \%$ were single. Most of the participants (47.2\%) were employed by the government or the private sectors. In terms of education level, most of the participants (50.7) were found to have bachelor degree. $21.7 \%$ of the participants lived in the rural and $78.3 \%$ in the urban areas.

\section{Hand washing}

The average frequency of hand washing between participants was found to be 15.28 times per day with minimum and maximum of 1 and 100, respectively. The average handwashing frequency in women was higher than in the men group, and the difference between two groups was statistically significant according to the t-test statistics $(p<0.05)$. The main explanation for this result may be attributed to this assumption that women pay more attention to their personal hygiene than men [17]. In addition, due to the fact that women in Iran are responsible for doing household chores, including cooking and cleaning, and therefore this can increase their responsibility in relation to the health of other family members.
The results obtained showed that married people washed their hands more compared to single people. However, the difference between two groups was not statistically significant based on the T-test statistics $(p<0.05)$. Among married people, those who had children washed their hands more than those who did not have children. The T-Test statistical test showed that the average hand washing frequency of two groups was significantly different. This result can be due to the responsibility of parents for the health of their and children. In addition, in the majority of Iranian families, fathers are responsible for financing the living expenses. Father's illness or death leads to temporary or permanent disruption of the family economy.

In terms of the average frequency of hand washing, there was no significant difference between urban and rural areas $(p>0.05)$.

The ANOVA statistics showed that there was a significant difference between different jobs in terms of the frequency of hand washing $(p<0.05)$. However, this difference was not statistically significant between participants with different education level.

The most effective cleaning agent for hand washing is liquid soap followed by, and solid soap is the next. $38.5 \%$ of the participants claimed that they use other ingredients, such as washing powder and dishwashing liquid, to wash their hands. 


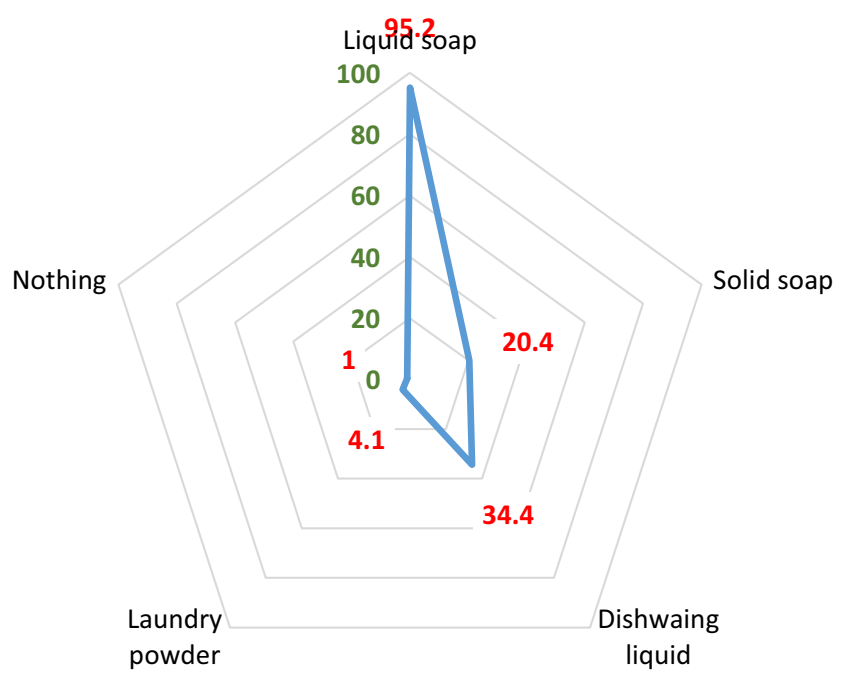

Fig. 1 The type of detergents applied for hand washing

The contribution of different detergent applied for hand washing are shown in the Fig. 1. Due to the presence of skin incompatible substances in these detergents, skin damage is possible for the consumers of these detergents. $1 \%$ of participants do not use any detergent to wash their hands. As water alone is not able to eliminate microorganisms, especially coronavirus, these people are at higher risk for coronavirus.
According to the world health organization (WHO), the

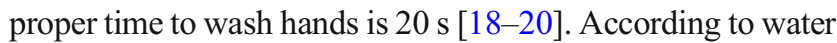
supply officials in Iran, the water consumption has increased by about $20-40 \%$ since initial stage of the outbreak of COVID-19 in Iran. It is worth noting that part of this water consumption is contributed to washing and cleaning the house in special days of the new year, which coincides with the outbreak of COVID-19.

\section{Hand sanitizing}

Approximately $77.9 \%$ of participants sanitize their hands when the outbreak of COVID-19 spread. In addition to the hands, disinfection of the feet, face and whole body was performed by $22.4,30.2$ and $13 \%$ of the participants, respectively. The average frequency of hand sanitization by participants was 10.74 times with a minimum and a maximum of 1 and 100, respectively. According to the t-test or ANOVA statistics, there was no significant difference in the number of hand disinfections between different people categorized by age, gender, level of education, marital status, having children, place of residence and occupation $(p>0.05)$.

The situations in which participants disinfect their hands are shown in the Fig. 2. As can be seen from the figure, most participants disinfect their hands after coming back to home,

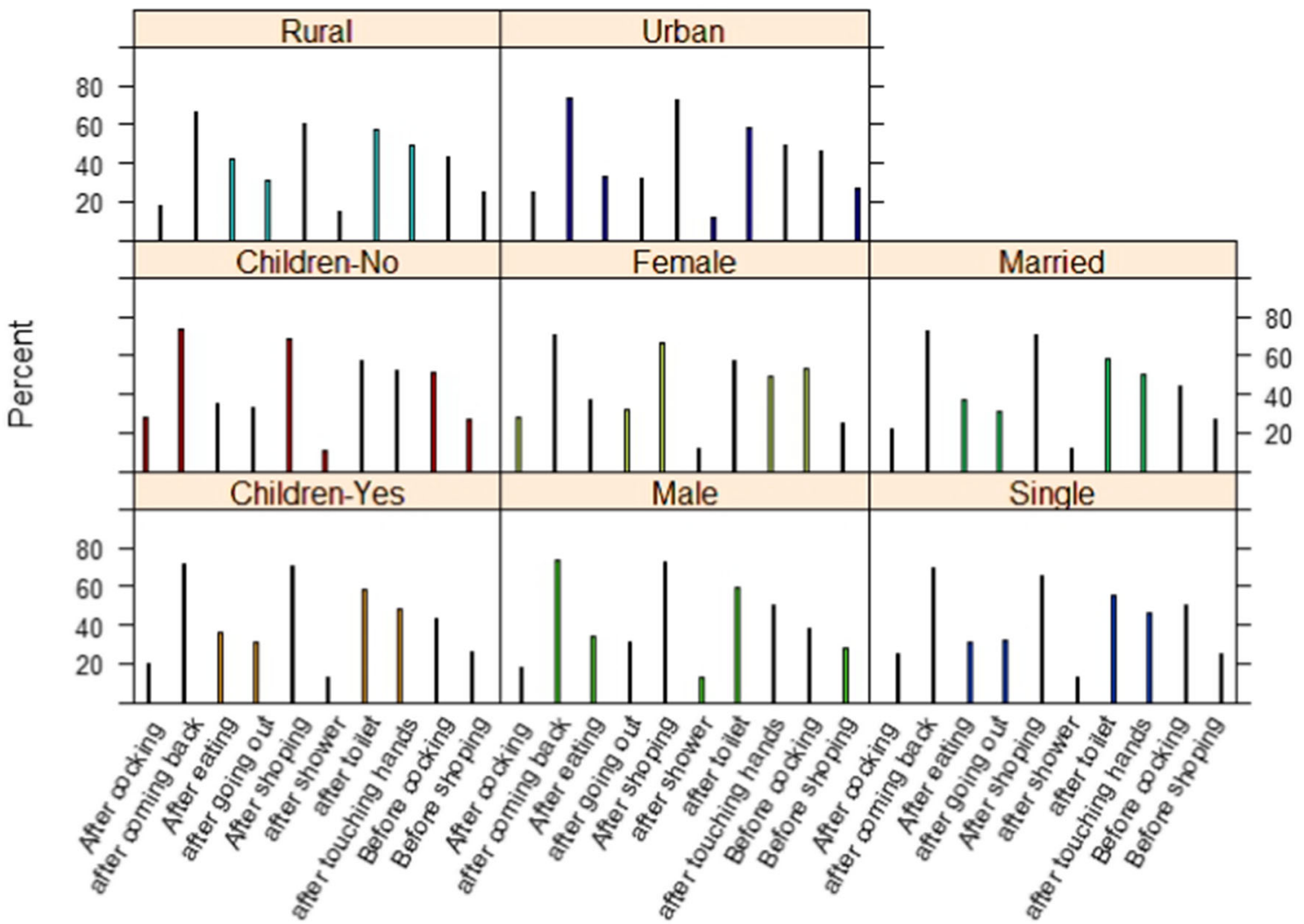

Situation

Fig. 2 The situations in which participants sanitize their hands 
after shopping, after going to the toilet, and after touching the hands of other. It is recommended that people disinfect their hands when doing certain activities, such as before and after eating, after going to the toilet, after shopping, and after touching contaminated or suspected surfaces of contamination. On the one hand, not disinfecting hands in the mentioned situations can increase the risk of spreading COVID-19, on the other hand, increases in the frequency of disinfections and overuse of these matters can cause adverse effects on consumer health. To overcome these problems, it is necessary to educate the people about the correct methods of hand disinfection.

Disinfection of the face, and feet was performed by 30.2 , $22.4 \%$ of the participants, respectively. $13 \%$ of participants disinfect their entire body. Apart from the hand, the recommendation to disinfect other parts of the body has not been reported so far [21, 22]. Over frequent disinfection of other organs, especially the face, can cause skin, eye, lung, and gastrointestinal disorders [23].

241 participants $(22.1 \%)$ reported that they did not disinfect their hands after the coronavirus virus outbreak. Of this group, $31.1 \%$ wash their hands less than 10 times a day. Since washing hands with soapy water as well as disinfecting hands with alcoholic solutions is recommended as the most important ways to prevent COVID-19 [24-26], the risk of getting COVID-19 further threatens the health of these persons.

\section{Surface disinfection}

$91 \%$ of participants disinfect surfaces. The average frequency of surface disinfection by participants was 2.99 times with a maximum of 30 and a minimum of 1 . The frequency of disinfections recommended for surfaces is $2[27,28]$. In addition

Fig. 3 The surfaces disinfected by participants to health problems, frequent disinfection of surfaces can also damage the family economy. According to the t-test or ANOVA statistics, there was no significant difference in the number of surface disinfections between different participants categorized by age, gender, level of education, marital status, having children, place of residence and occupation.

The most important surfaces disinfected by participants were toilet $(80.7 \%)$, keys $(86.1 \%)$, credit card $(87 \%)$, and mobile phone $(86.6 \%)$. The frequency of disinfection of other surfaces by the participants is shown in the Fig. 3 .

The correlations between hand washing frequency, hand sanitizing frequency and surface disinfection frequency are shown in Fig. 4. The correlation between hand washing and hand sanitizing frequency was 0.61 , while the correlation between hand washing and surface disinfection frequency, and between hand sanitizing and surface disinfection frequency were 0.16 and 0.28 and all of them were significant at level of 0.05 .

\section{Disinfectants}

The most commonly used substance by participants to disinfect their hands was found to be alcoholic solutions (51.4\%). $4.8 \%$ of people use sodium hypochlorite bleach and $43.8 \%$ use other substances. Alcohol is not available for everyone due to its high cost and scarcity. Some people, mostly lowincome people, use Sodium hypochlorite bleach to disinfect their hands due to its low cost and availability. Although lowconcentration of sodium hypochlorite bleach $(0.05 \%)$ can be used for hand disinfection [29-31], uses of sodium hypochlorite bleach with high concentration are limited unless in emergency conditions. Repeated use of sodium hypochlorite bleach with inappropriate concentrations can cause damage

$\square$ YES $\square$ NO

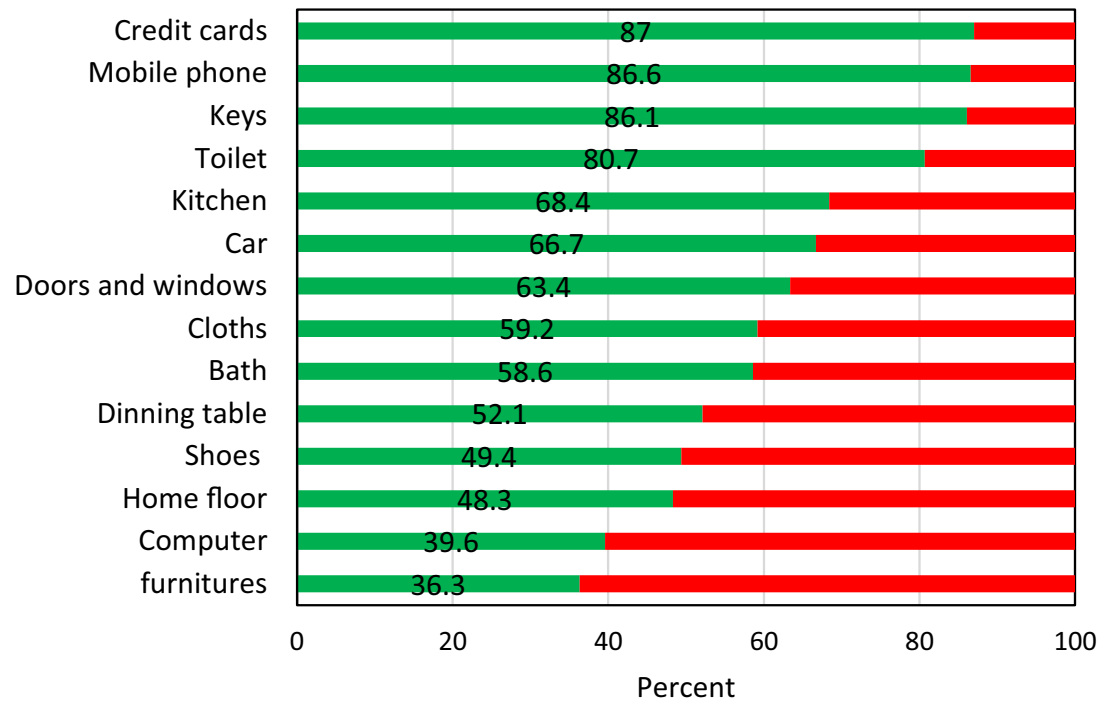




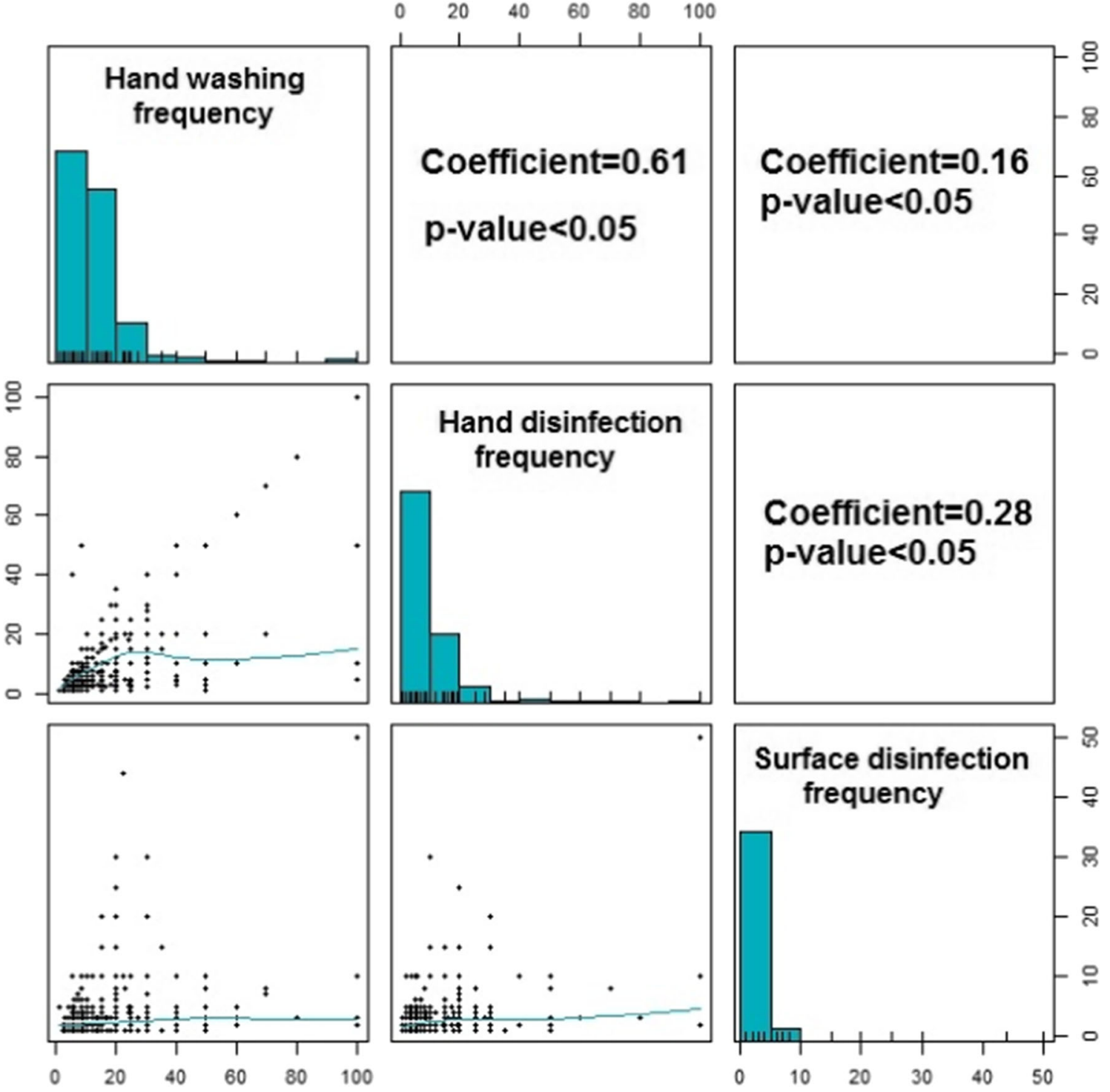

Fig. 4 Correlation between hand washing frequency, hand disinfection frequency, and surface disinfection frequency according to spearmen rank correlation coefficient

to the skin of the hands and respiratory problems for these people. Some people have also resorted to the use of natural and herbal disinfectants such as vinegar. Given that the effectiveness of these disinfectants has not been proven by scientific sources [32-34], their use causes a false sense of the safety, and the risk of afflicting these people to COVID-19 is increased.

sodium hypochlorite bleach is the most widely used disinfectant for surfaces disinfection by individuals $(57.3 \%)$. The next ranks belong to the alcohol solution (22.6\%). $20.2 \%$ of participants use other materials than these for surface disinfection. Lack of proper training to people to prepare and use sodium hypochlorite bleach can cause irreparable damage to their health. The best way to use sodium hypochlorite bleach for surface disinfection is to soak the fabric in sodium hypochlorite bleach and draw it on the surfaces. Spraying sodium hypochlorite bleach on surfaces, in addition to spreading sodium hypochlorite bleach itself in the air, removes contaminants from the surfaces and suspend them in the air [35].

Correct time for disinfection is another point that, if not followed properly, the disinfection efficiency will be reduced. The appropriate time for disinfection by sodium hypochlorite bleach $(0.5 \%)$ is at least $10 \mathrm{~min}$ [36]. Only $5.5 \%$ of participants consider this contact time. $21.6 \%$ of people claimed that they start drying surfaces immediately after using sodium hypochlorite bleach. Due to the lack of contact time, the efficiency of the disinfection process will be reduced.

\section{Disinfectants preparation}

$38.6 \%$ of participants buy ready-to-use disinfectant solutions, and $61.4 \%$ buy the raw materials and mix them at home with 
other substances such as water to make them ready for use. Alcohol-based solutions and sodium hypochlorite bleach are the most widely used disinfectants by participants after the outbreak of Coronavirus.

$2.1 \%$ of participants mix alcohol with substances other than water. The reaction of these substances with alcohol can lead to the production of harmful secondary compounds that are harmful to health. Due to the facts that the appropriate concentration of ethanol for disinfection is 60 to $70 \%$ [37-40] and the alcohol available in the market mainly has a concentration higher than 95-99\%. The best way to prepare an alcohol solution to disinfect the hands and surfaces is mixing three cup of $99 \%$ alcohol with one cup of water [41, 42]. This method has been followed only by $10 \%$ of participants. Other patterns used by people neither have the necessary effectiveness for disinfection, nor have adverse health effects on consumers. $40 \%$ of participants do not follow the correct pattern of mixing alcohol with water.

The correct pattern for mixing sodium hypochlorite bleach) $5 \%$ active chlorine(with water to prepare a concentration of $0.1 \%$ chlorine suitable for disinfection of surfaces is one cup of sodium hypochlorite bleach with 49 cup of water [43]. About $82 \%$ of the participants used a different method other than the aforementioned pattern to prepare the sodium hypochlorite bleach solution. Approximately $0.7 \%$ of people have used the sodium hypochlorite bleach in a concentrated form without mixing it with water, which can have very adverse effects on their health. Approximately $1.3 \%$ of participants mix sodium hypochlorite bleach with other substances than water. Secondary substances produced by the reaction of these substances may have an adverse effect on consumer health [44].

\section{Safety issues}

The use of personal protective equipment (PPE) such as masks and gloves is one of the requirements when uses of surface disinfectants $[13,45]$. $47.5 \%$ of people didn't use any personal protective equipment when using disinfectants for surfaces, which endangers their health. The PPE used by consumers were shown in Fig. 5.

In Iran, the National Radio and Television are known as the most important and reputable source of news related to COVID-19, and the people have been advised to follow the news and recommendations for the preventive measurements against COVID-19 through these media. Selected references by participants to obtain instructions on the use of disinfectants are shown in Fig. 6. As can be seen from this figure, the highest contribution belongs to social networks $(55.3 \%)$, followed by radio and television (43.8\%). Although social media has played an undeniable role in informing about COVID-19, a large number of unscientific recommendations have been spread through social networks. The $\square Y$ Y $\square$ NO

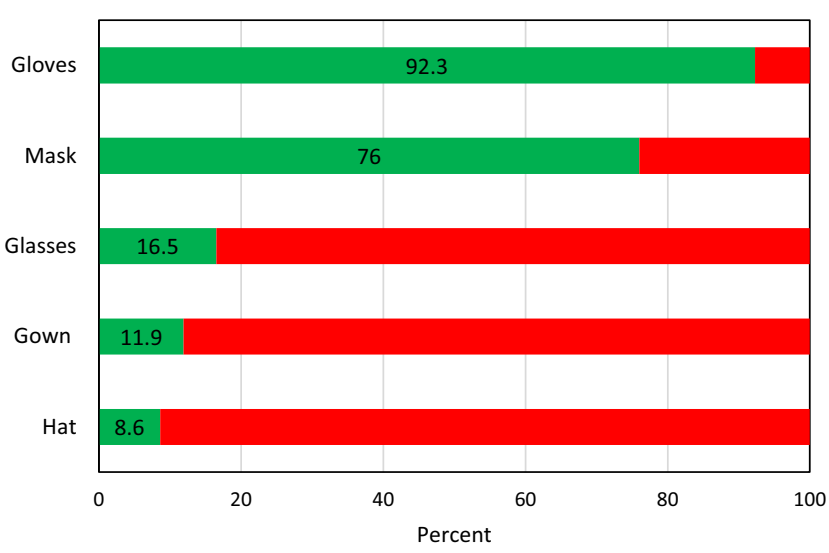

Fig. 5 PPE used by participants when they are disinfecting the surfaces

implementation of this recommendation by some people has caused irreparable damage to their health. Advices to use methanol instead of ethanol for disinfecting hands and surfaces and drink alcohol to remove the virus from the body were those that have led to poisoning, blindness and even death in some people.

$5.4 \%$ of participants have used methanol (red or industrial alcohol) instead of ethanol (white or medical alcohol) for disinfection. Due to the proven adverse effects of methanol such as blindness, skin damage and even death [46-48], its use for disinfecting body organs and surfaces is strictly prohibited.

$15.4 \%$ of the participants provide disinfectants from centers other than pharmacies and health centers. The huge profits from the sale of disinfectants after the outbreak of the coronavirus have led some profiteers to produce counterfeit disinfectants using hazardous chemicals; many of disinfectants produces have been seized by legal authorities [49, 50]. Therefore, it is recommended that people obtain disinfectants from reputable centers and stores and ensure the safety of these substances.

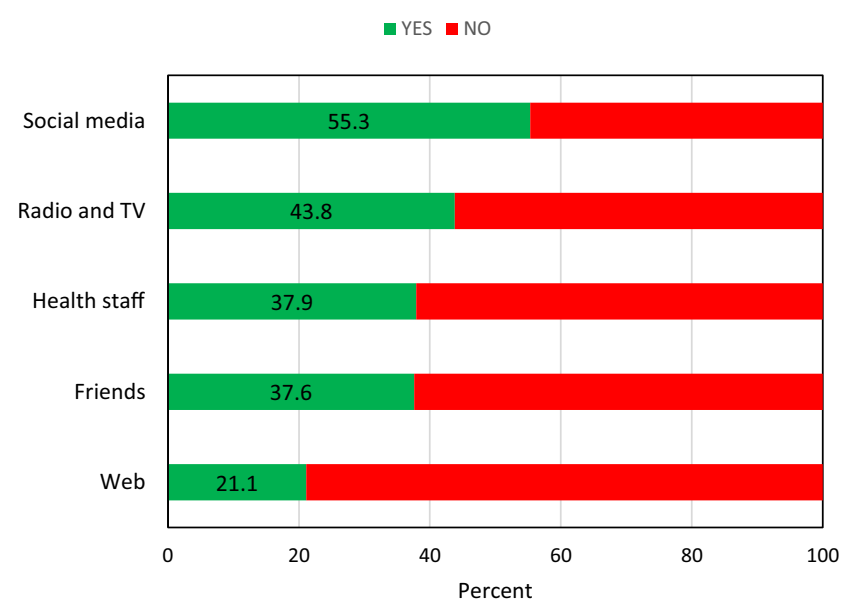

Fig. 6 The references used by participants to obtain information regarding disinfectants 
$65.2 \%$ of people keep disinfectants in inappropriate places such as kitchens, bedrooms, toilets and bathrooms. Storage of disinfectants and disposal of empty containers is one of the points that must be done correctly in terms of safety. Keeping disinfectants available to children and near food items can cause poisonous effects on family members. The best place to store these materials is in a warehouse, away from family members and flammable materials [51-55]. In addition, the appropriate temperature and storage time for these materials must be considered according to the manufacturer's instructions.

Regarding the majority of chemicals, including disinfectants, it is recommended that their empty containers must be delivered separately from other waste to organizations that are responsible for managing such waste. $70.3 \%$ of participants dispose empty containers, along with other waste, which can be detrimental to the health of waste collection personnel and cause possible fires at waste storage and disposal sites.

\section{Adverse effect of disinfectants}

$41.4 \%$ of participants had health problems in at least one organ of their body due to the use of disinfectants. The results of the adverse effects of disinfectants observed between the participants re shown in Fig. 7.

The most important skin effects on the hands and feet, were found to be itching, redness, dryness, and sores. Eye effects included eye irritation and itching, tearing, and decreased vision. Lung irritation, shortness of breath, cough and sneezing are some of the frequent effects observed in the respiratory system. Abdominal pain, diarrhea and vomiting have been common gastrointestinal symptoms.

Throat irritation, obsessive-compulsive disorder, lack of concentration, headaches and dizziness and fatigue have been other adverse effects of disinfectants on people. In addition,

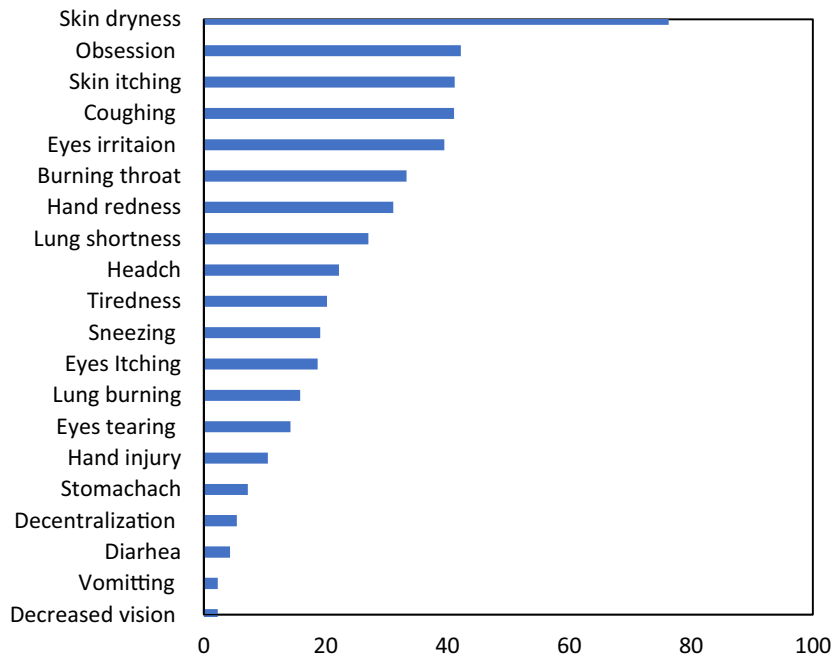

Fig. 7 The impacts of disinfectants observed in participants
$1.7 \%$ of participants claimed that they or their relatives had eaten disinfectants, including alcohol, to treat coronavirus and had to see a doctor because of its side effects.

\section{Conclusion}

In this study, the pattern of preparation and consumption of disinfectants after corona outbreak and adverse effects of these substances on consumer health were examined. The results indicated that a significant number of participants are unfamiliar with the principles of preparation and use of disinfectants. Improper preparation, uses of disinfectants in unconventional concentrations, storage in unsafe places, excessive use of these materials, receiving instructions for the use of these materials from unreliable sources and improper disposal of empty containers are the most important mistakes made by participants. Because the misuse of these substances can have irreversible effects on people's health, it is necessary for health authorities to provide the necessary training for consumers from official and reputable authorities.

Acknowledgments We are sincerely thankful to Social Determinants in Health Promotion Research Center, Hormozgan Health Institute, Hormozgan University of Medical Sciences for funding this research.

\section{Compliance with ethical standards}

Conflict of interests The authors declare that there is no conflict of interests.

\section{References}

1. Chen Y, Liu Q, Guo D. Emerging coronaviruses: genome structure, replication, and pathogenesis. J Med Virol. 2020.

2. Wilder-Smith A. The severe acute respiratory syndrome: impact on travel and tourism. Travel Med Infect Dis. 2006;4(2):53-60.

3. Zhou P, Yang X-L, Wang X-G, Hu B, Zhang L, Zhang W et al. Discovery of a novel coronavirus associated with the recent pneumonia outbreak in humans and its potential bat origin. BioRxiv. 2020.

4. Chang D, Xu H, Rebaza A, Sharma L, Cruz CSD. Protecting health-care workers from subclinical coronavirus infection. Lancet Respiratory Med. 2020.

5. Menachery VD, Dinnon KH, Yount BL, McAnarney ET, Gralinski LE, Hale A et al. Trypsin Treatment Unlocks Barrier for Zoonotic Bat Coronavirus Infection. J Virol. 2020;94(5).

6. Harapan H, Itoh N, Yufika A, Winardi W, Keam S, Te H, et al. Coronavirus disease 2019 (COVID-19): a literature review. J Infect Public Health. 2020;13(5):667-73. https://doi.org/10.1016/j.jiph. 2020.03.019.

7. Huang C, Wang Y, Li X, Ren L, Zhao J, Hu Y, et al. Clinical features of patients infected with 2019 novel coronavirus in Wuhan, China. Lancet. 2020;395(10223):497-506.

8. Bernheim A, Mei X, Huang M, Yang Y, Fayad ZA, Zhang N et al. Chest CT Findings in Coronavirus Disease-19 (COVID-19): relationship to duration of Infection. 2020:200463. 
9. Zhu N, Zhang D, Wang W, Li X, Yang B, Song J et al. A novel coronavirus from patients with pneumonia in China, 2019. N Engl J Med. 2020;382:727-33.

10. Worldometer. COVID-19 CORONAVIRUS PANDEMIC, https:// www.worldometers.info/coronavirus/ 2020.

11. Faridi S, Niazi S, Sadeghi K, Naddafi K, Yavarian J, Shamsipour $\mathrm{M}$, et al. A field indoor air measurement of SARS-CoV-2 in the patient rooms of the largest hospital in Iran. Sci Total Environ. 2020;725:138401. https://doi.org/10.1016/j.scitotenv.2020. 138401.

12. Takian A, Raoofi A, Kazempour-Ardebili S. COVID-19 battle during the toughest sanctions against Iran. Lancet (London, England). 2020;395(10229): 1035 .

13. Ranney ML, Griffeth V, Jha AK. Critical supply shortages - the need for ventilators and personal protective equipment during the Covid-19 pandemic. N Engl J Med. 2020;382:e41.

14. WHO. Water, sanitation, hygiene and waste management for COVID-19: technical brief, 03 March 2020: World Health Organization 2020.

15. Kampf G, Todt D, Pfaender S, Steinmann E. Persistence of coronaviruses on inanimate surfaces and their inactivation with biocidal agents. J Hosp Infect. 2020;104(3):246-51.

16. hums. Situation report -COVID 19 on 18 May 2020. [Internet] hormozgan university of medical sciences.

17. Alnakli Z. Saudi Arabians' health beliefs pertaining to Middle East respiratory syndrome-Coronavirus (MERS-CoV): knowledge, attitudes, and practices (KAP) assessment. 2016.

18. Joshi P. Practical-10 disinfection and house keeping. IGNOU; 2018.

19. Organization WH. Improving infection prevention and control at the health facility: interim practical manual supporting implementation of the WHO Guidelines on Core Components of Infection Prevention and Control Programmes: World Health Organization 2018.

20. Mohammed K Corona virus. 2020.

21. Marriott NG, Schilling MW, Gravani RB. Personal Hygiene. Principles of Food Sanitation. Springer; 2018. p. 93-108.

22. Sanitizer A-BH. Handwashing and hand Sanitizer use at home, at play, and out and about. 2020.

23. Lachenmeier DW. Safety evaluation of topical applications of ethanol on the skin and inside the oral cavity. J Occupation Med Toxicol. 2008;3(1):26.

24. Adams D, Quayum M, Worthington T, Lambert P, Elliott T. Evaluation of a $2 \%$ chlorhexidine gluconate in $70 \%$ isopropyl alcohol skin disinfectant. J Hosp Infect. 2005;61(4):287-90.

25. Madani TA, Althaqafi AO, Alraddadi BM. Infection prevention and control guidelines for patients with Middle East respiratory syndrome coronavirus (MERS-CoV) infection. Saudi Med J. 2014;35(8):897-913.

26. Sprenkle A Coronavirus Explainer. 2020

27. Kim KM, Han SH, Yoo SY, Yoo J-H. Potential hazards of concern in the walk-through screening system for the corona virus disease 2019 from the perspective of infection preventionists. J Korean Med Sci. 2020;35(15)

28. Kampf G, Todt D, Pfaender S, Steinmann E. Persistence of coronaviruses on inanimate surfaces and its inactivation with biocidal agents. J Hospital Infect. 2020.

29. Hsieh S-C, Teng N-C, Chu CC, Chu Y-T, Chen C-H, Chang L-Y, et al. The antibacterial efficacy and in vivo toxicity of sodium hypochlorite and electrolyzed oxidizing (EO) water-based endodontic irrigating solutions. Materials. 2020;13(2):260.

30. Gerba CP, Kennedy D. Enteric virus survival during household laundering and impact of disinfection with sodium hypochlorite. Appl Environ Microbiol. 2007;73(14):4425-8.

31. Parnes CA. Efficacy of sodium hypochlorite bleach and" alternative" products. J Environ Health. 1997;59(6):14.
32. Amin M, Han M. Improvement of solar based rainwater disinfection by using lemon and vinegar as catalysts. Desalination. 2011;276(1-3):416-24.

33. Tijare M, Smitha D, Kasetty S, Kallianpur S, Gupta S, Amith H. Vinegar as a disinfectant of extracted human teeth for dental educational use. J Oral Maxillofacial Pathol: JOMFP. 2014;18(1):14 8.

34. Rutala WA, Barbee SL, Aguiar NC, Sobsey MD, Weber DJ. Antimicrobial activity of home disinfectants and natural products against potential human pathogens. Infect Contrl Hospital Epidemiol. 2000;21(1):33-8.

35. Hacek DM, Ogle AM, Fisher A, Robicsek A, Peterson LR. Significant impact of terminal room cleaning with bleach on reducing nosocomial Clostridium difficile. Am J Infect Control. 2010;38(5):350-3.

36. Perez J, Springthorpe VS, Sattar SA. Activity of selected oxidizing microbicides against the spores of Clostridium difficile: relevance to environmental control. Am J Infect Control. 2005;33(6):320-5.

37. Chambers S, Peddie B, Pithie A. Ethanol disinfection of plasticadherent micro-organisms. J Hosp Infect. 2006;63(2):193-6.

38. Sattar S, Springthorpe V, Karim Y, Loro P. Chemical disinfection of non-porous inanimate surfaces experimentally contaminated with four human pathogenic viruses. Epidemiol Infect. 1989;102(3):493-505.

39. Jordan CN, DiCristina JA, Lindsay DS. Activity of bleach, ethanol and two commercial disinfectants against spores of Encephalitozoon cuniculi. Vet Parasitol. 2006;136(3-4):343-6.

40. Malik YS, Maherchandani S, Goyal SM. Comparative efficacy of ethanol and isopropanol against feline calicivirus, a norovirus surrogate. Am J Infect Control. 2006;34(1):31-5.

41. Wakisaka A, Matsuura K. Microheterogeneity of ethanol-water binary mixtures observed at the cluster level. J Mol Liq. 2006; 129(1-2):25-32.

42. Todd EC, Michaels BS, Holah J, Smith D, Greig JD, Bartleson CA. Outbreaks where food workers have been implicated in the spread of foodborne disease. Part 10. Alcohol-based antiseptics for hand disinfection and a comparison of their effectiveness with soaps. $\mathrm{J}$ Food Prot. 2010;73(11):2128-40.

43. Organization WH. Cleaning and disinfection of environmental surfaces in the context of COVID-19: interim guidance, 15 May 2020: World Health Organization 2020.

44. Rutala WA, Weber DJ. Uses of inorganic hypochlorite (bleach) in health-care facilities. Clin Microbiol Rev. 1997;10(4):597-610.

45. Organization WH. Rational use of personal protective equipment (PPE) for coronavirus disease (COVID-19): interim guidance, 19 March 2020: World Health Organization 2020.

46. Darwish A, Roth C, Duclos P, Ohn S, Nassar A, Mahoney F, et al. Investigation into a cluster of infant deaths following immunization: evidence for methanol intoxication. Vaccine. 2002;20(29-30): 3585-9.

47. Rietjens S, De Lange D, Meulenbelt J. Ethylene glycol or methanol intoxication: which antidote should be used, fomepizole or ethanol. Neth J Med. 2014;72(2):73-9.

48. Ghosh P, Peters J. Impulsive differential equation model in methanol poisoning detoxification. J Math Chem. 2020;58(1):126-45.

49. Khan N, Fahad S, Naushad M. Climate Impact on Corona Virus in the World.

50. Singh C, Rakshit P. A critical analysis to comprehend panic buying behaviour of Mumbaikar's in COVID-19 era. Studies in Indian Place Names. 2020;40(69):44-51.

51. Spann MF, Blondell JM, Hunting KL. Acute hazards to young children from residential pesticide exposures. Am J Public Health. 2000;90(6):971-3.

52. Habib RR, El-Masri A, Heath RL. Women's strategies for handling household detergents. Environ Res. 2006;101(2):184-94. 
53. Misra V, Pandey S. Hazardous waste, impact on health and environment for development of better waste management strategies in future in India. Environ Int. 2005;31(3):417-31.

54. Dean LF. Household hazardous materials and their labels: a reference for teachers. 1989.
55. Steinwachs M. Store hazardous products safely: your home may be an accident waiting to happen (1993). 1993.

Publisher's note Springer Nature remains neutral with regard to jurisdictional claims in published maps and institutional affiliations. 